\title{
Comparative Study of the Electrical, Thermal and Mechanical properties of Polypyrrole/CB/and Copper nano powder reinforced Polyester Hybrid Composites
}

\section{Sumaira Nosheen ( $\nabla$ sumera_pcsir@yahoo.com )}

Pakistan Council of Scientific and Industrial Research

Syed Hussain Abidi

PCSIR Head Office, Constitution Avenue Islamabad, Pakistan

Quratulain Syed

Pakistan Council of Scientific and Industrial Research

Muhammad Irfan

Pakistan Council of Scientific and Industrial Research

Farzana Habib

Pakistan Council of Scientific and Industrial Research

\section{Badaruddin Soomro}

Pakistan Council of Scientific and Industrial Research

\section{Research Article}

Keywords: Polymer, Composite, Hybrid, Mechanical, Thermal

Posted Date: December 30th, 2021

DOI: https://doi.org/10.21203/rs.3.rs-1206728/v1

License: (c) (i) This work is licensed under a Creative Commons Attribution 4.0 International License.

Read Full License 


\section{Abstract}

The present research work based on Synthesis and characterization of Polypyrrole coated CB (carbon black), Copper, and VGCNF (vapor grown carbon nanofibers) hybrid composite. Two approaches were used comprising in situ polymerization of Polypyrrole/CB composite. The resulting composite was dispersed in with the measured quantity of Cu nano Powder and VGCNF in polyester at very high rate of dispersion to produced hybrid composite. The resulting composites were characterized by FTIR, electrical conductivity, mechanical properties, thermal analysis and UV visible spectroscopy.

\section{Introduction}

Polymers is a big class of materials have very diversity in nature due to having some unique properties they are helpful in the synthesis of idyllic materials which can have easy processing lightweight, and wanted mechanical properties. Therefore, these high temperature withstanding resins has wide application in aeronautical industry. The main advantage of developing hybrid composites is to enhance the properties of composites and to make them more functional for diversified applications. Several researchers developed hybrid composites and reported improved properties of resulting composites. E.g, raza et al. [1] reported graphite nano platelet /carbon black (CB) /epoxy composites. They reported improvement in mechanical and electrical properties by incorporation of $\mathrm{CB}$. They also reported that the good dispersion and high loading \%age of fillers lead to increase the thermal stability.

Nano composites is an extensive class of composites which consist of multiphase solid materials in which at least one component is in nano scale (i.e. in the range of zero to 3D with the length of less than $100 \mathrm{~nm})$. Nanocomposites not only show remarkable difference from the conventional materials but also differ from the individual component used in the synthesis of these composites. That's why they show improved mechanical, electrochemical, optical, thermal stability, corrosion protection, enhanced Chromium absorption ability, and many more due to high surface to volume ratio. [2 ] More over CNTs also effect on the mechanical properties of polymer especially when it dispersed into the polymer matrix to form composite. [3, 4]

Polymers with extended conjugated carbon-carbon double bonds can be named as electrically conducting polymers [4]. In terms of their properties the conducting polymers are recognized as new materials. The first conducting polymer was investigated in nineteenth century. Henry Lethe prepared poly aniline in 1862 by electrochemical method, which not only shows the conduction but also exhibit electro chromic behavior [6-8]. Poly acetylene as a black powder was synthesized by Natta et al. in 1958 and it was found to be semiconductor with the conductivity ranges from $10^{-11}$ to $10^{-3}$ depends upon the process ability of the polymer. [6]

The doped poly acetylene was reported in 1977 as a first ICP. [2] After the preparation of poly acetylene by Sirakawa and coworkers a new field of research was actually launched by the group led by MacDiarmid and Heeger who discovered that the doping method cannot only helps us to increase the electrical 
conductivity, but also used to monitor the martial properties in response to their electrochemical properties [7]. This electro active class of polymers gains more importance in the field of science when Nobel Prize was awarded in the field of chemistry to Shirakawa and his coworkers in 2000 [6, 7]. The composition of any material is very useful to establish the electrical properties in a certain material. The band theory is most useful way to describe the electronic structure of any electrically conducting materials. Quantum mechanism shows that the electrons have quantized energy level which forms bands. The highest and outer most occupied band is called as valance band while highest and the lowest unoccupied levels termed as the conduction bands. These ICPs specially used as hetero junction polymeric materials, polypyrrol coated n-type silicone based solar cells have been synthesized by electrochemical method. Similarly, the electrodes for rechargeable batteries had also been reported [614].

The conductivity of these polymers can be enhanced by introducing highly conductive fillers at very high loading as high as $80 \%$ by weight with the polymer matrix such as silver, gold and graphite powders to meet the requirements of electronic industry. A part from these benefits, there are copious disadvantages also exist with these polymers for example there high-cost wear and tear environmental stability and many other properties of the polymer [15]. The PP/PPy and PP/CB composites and pure PP were synthesized by melt mixing while pure PPy is prepared by chemical method. They observed that the composites which are synthesized by melt mixing exhibit good electrical properties then the composite which is prepared by the chemical method. More over even the small amount of PPy if introduce in the polymer matrix it is sufficient to enhance the electrical properties of the PP/PPy composite was reported. Hence this property will also be affected by the processing conditions used to synthesize this composite [16].

\section{Materials And Methods}

PPy was synthesized by using pyrrole monomer (sigma Aldrich). About $8.65 \mathrm{ml}$ along with $25 \mathrm{ml}$ DI water was taken in the round bottom flask assisted with overhead mechanical stirrer. The mixture was stirred for 10 minutes. Then $2.5 \mathrm{M} \mathrm{FeCl} 3$ was added drop wise which acted as an oxidizing agent. The polymerization started immediately which was observed from the formation of black particles in the solution. [17]. The weighted amount of the CB was dispersed in the solvent along with continuous stirring. The $25 \%$ aqueous ethanol was found to be the most effective solvent for well dispersion of the $\mathrm{CB}$. The solution containing $\mathrm{CB}$ was stirred on a disperser machine at the rate of $600 \mathrm{rpm}$ for $20 \mathrm{~min}$ and then this solution was ultrasonicated for $30 \mathrm{~min}$. The pyrrole monomers was added into it and disperse for 10 min so that monomer diffused onto the surface of $\mathrm{CB}$ and $2.5 \mathrm{MFeCl}_{3}$ was added drop wise. This solution was allowed to stir for 24 hours so that the Pyrrole monomer polymerized on the surface of CB. The resultant composite was filtered to remove $\mathrm{FeCl}_{2}$ indicated in the form of green color from the final product by washing it with de ionized water and ethanol, respectively, till the green color discharged. Then finally the filtered composite dried in vacuum oven at $70^{\circ} \mathrm{C}$ for 10 hours. After drying the yield of the 
prepared composite was calculated. The same recipe was used for the synthesis of this composite with different \%ages of $\mathrm{CB}(3,5,10,15$, and 20 wt $\%)$.

\section{Synthesis of PPy /CB with polyester composites}

Polypyrrole coated carbon black was mixed with polyester resin by high shear mixer at speed of $\sim 6,000$ rpm for 10 min. The composites were prepared by mixing PPy coated CB at 3, 5, 7 wt. \% ages respectively. After mixing filler in polyester resin cobalt naphthalate and methyl-ethyl ketone peroxide was added as curing agent and the mixture was immediately poured into custom made molds for curing purpose. The curing procedure was completed in vacuum oven at room temperature

\section{Synthesis of PPy coated CB/Cu nano powder/polyester hybrid composites}

The PPy coated CB and copper powder was dispersed in polyester resin to produce composite. 5\% PPy coated carbon black was used for development of hybrid composite. The composites were prepared at 5 , $10,15,20 \mathrm{wt} \%$ of Cu nano powder. The Cu nano powder was dispersed into polyester by high shear mixer at speed of $\sim 6,000 \mathrm{rpm}$ for $10 \mathrm{~min}$. The curing procedure is same as described in PPy/CB polyester composite.

\section{Synthesis of PPy coated CB/Cu nano powder/ VGCNF polyester hybrid composites}

The PPy coated CB/Cu/VGCNF hybrid composites were produced by dispersing all of these nano fillers in polyester by high share mixing at speed of $\sim 8,000 \mathrm{rpm}$. The time of mixing for each filler was $10 \mathrm{~min}$. The composite was prepared at $5,7,10,12 \mathrm{wt} \%$ of VGCNF. Due to high speed of mixing the dispersion temperature increased significantly. This dispersion was then cooled in ice after the mixing of each filler and also prior to the addition of curing agent. The curing procedure is same as described in $\mathrm{PPy} / \mathrm{CB}$ polyester composites. The pure polyester composite was also prepared by the same method.

\section{Results And Discussions}

The FTIR spectra (Fig. 1) show the comparative analysis of pure PPy and PPy/CB composite. The presence of a strong signal at $3612 \mathrm{~cm}^{-1}$ is due to the presence of $\mathrm{N}-\mathrm{H}$ in the pyrrole ring. Composite also shows the same vibration in that region. In the Fig. 4.1 (b) some new peaks has been noticed in the regions of $500-600 \mathrm{~cm}^{-1} 2250-3000 \mathrm{~cm}^{-1} 1$ and weak signals also seen in the region of $1000-1400 \mathrm{~cm}^{-1}$ which indicated that the polymer has strong attraction with $\mathrm{CB}$ due to the presence of some functional groups on the surface of $\mathrm{CB}$. The peaks characterized in the existing work are quite similar with the data presented in literature that confirms the synthesis of polymer. [48-49]

\subsection{Thermo gravimetric analysis}

Hybrid composites were synthesized to check the effects on the properties of polyester by the addition of this composite, cu nano particles, and carbon nano tubes. This relation has been noticed in the Fig. 2 
which displays that all these components impart good thermal stability to the Polyester. TGA behavior of these hybrid composite interprets that by the incorporation of PPy and PPy/CB composite to the polyester do not shows significant effect comparatively as they retain the $80 \%$ and $81 \%$ mass at the temperature of $320^{\circ} \mathrm{C}$ and $340^{\circ} \mathrm{C}$ respectively. But when the $\mathrm{Cu}$ nano particles were added to the system it causes to increase the thermal stability and shows TGA at $360^{\circ} \mathrm{C}$ with the loss of $18 \%$ mass which is a good effect just at $5 \%$ loading of Cu nano particles. Similarly, the introduction of VGCNF at $5 \%$ loading imparts very good effects that it becomes stable even at $400^{\circ} \mathrm{C}$ and retains $87 \%$ mass and then shows rapid decomposition and finally all these materials decomposed at $900^{\circ} \mathrm{C}$.

\subsection{Electrical conductivity}

One main important thing is that cu nanoparticles should impart good electrical properties but their behavior is negligible. The reason behind that although these particles are conductive in nature but they reduce the conductivity in composite of polyester because they lose their entire contact with each other as if some of them as coated with polyester and this also indicates that quality of dispersion is very good. Table 1 presents the conductivity of hybrid composites one main and important thing noticed here that all the materials which are used in the synthesis of these hybrid composites are conductive in nature hence its conductivity must be higher but it is not. Rather it shows the conductivity level even less than that of the other two tables. There are two main reason in the synthesis of this hybrid composite various fillers with different conductivity encounters with each other might be due to the evolution of gasses during the process of curing some voids also left behind which also tend to kept apart the fillers and reduced the conductivity. The second is the good dispersion and coating of polyester on the surfaces of these fillers also suppressed the conductivity and the main cause to reduce the contact with each other.

Table 1

Comparative analysis of various filler effect on the conductivity of polyester

\begin{tabular}{|ll|}
\hline Composites ( $5 \%$ loading) & Conductivity S/m \\
\hline Polyester + PPy & $1.24 \times 10^{-2}$ \\
\hline Polyester + (PPy+C) & $1.54 \times 10^{-2}$ \\
\hline Polyester + Cu & $0.27 \times 10^{-3}$ \\
\hline Polyester + (PPy+C) $+\mathrm{Cu}$ & $5 \times 10^{-6}$ \\
\hline Pure polyester & Highly resistive \\
\hline
\end{tabular}

\subsection{Scanning Electron Microscopy}

The SEM studies were carried out to get the information of surface morphology of synthesized materials. The synthesis of pure polypyrrole is confirmed after taking the image (a) its results are comparable with 
the literature [52]. The image (b) indicates the carbon nano particles are coated with Polypyrrole. It also shows some agglomerates while image $(c, d, e)$ shows the images of hybrid composites in which it is clearly seen the formation of agglomerates which is the main area can produce the cracks due to reduce in attraction between the filler and matrix.

Spike like out growths confirms the presences of VGCNF and also demonstrate the good dispersion of VGCNF moreover it also shows that some of VGCNF are also coated with polyester that is the symbol of the good interaction between VGCNF and polyester Apart from these the presences of some voids due to the elimination of gases while curing which may effect on the net properties of the resultant material.

\subsection{Optical microscopy}

The optical images of hybrid composites are shown in Fig. 4. Many voids and holes were seen on the surface and these voides initiated cracks as clear from optical micrographs. Moreover some golden shiny spots indicates the presences of agglomerates of $\mathrm{Cu}$ nanoparticles and also indicates that the quality of dispertion of Cu nanoparticales is not as much good as it should be.

\subsection{Compression testing}

The samples were also assessed by their compressive values to judge if composites are hard enough to be used in certain other applications. Table 2 shows that the addition of various concentration of PPy coated carbon black composite in the pure polyester affect the compressive strength of the polyester. It is noticed that by adding $2 \%$ of PPy coated carbon black composite its strength has been decreased but increased gradually by raising the concentration and when it is raised up to $7 \%$ it tends to raise the strength up to $20 \%$ of pure polyester this effect can also see in the fig.

Table 3 indicates that cu nano particles imparts good mechanical properties to polyester and if its concentration raised up to $20 \%$ along with the $5 \%$ PPy /CB composite the resultant hybrid composite is $\sim 59 \%$ more stronger than pure polyester Fig. 5 while to check the combined effect of composite, VGCNF and $5 \% \mathrm{Cu}$ nano particles on the mechanical properties of polyester the hybrid composites of $12,10,7$ and $5 \%$ were assessed for compression testing which indicated theta although the $12 \%$ loading of VGCNF imparts 15\% more strength than polyester but this is value is much less than that of Cu nano particles alone the reason behind due to the huge interaction of Different particles their association with the polyester suppressed due to which some primary cracks or voids are left behind during the process of curing. Hence when the load applied on these samples they starts breaking from these spots as they can clearly seen in the optical microscopy images.

Table 2ompressive strength of $(\mathrm{PPy}+\mathrm{C})$ / polyester hybrid composite 


\begin{tabular}{|l|l|l|}
\hline Sr.\# & $\begin{array}{l}\text { Sample ID with various } \\
\text { \%age PPy/CB in polyester }\end{array}$ & $\begin{array}{l}\text { Compressive strength } \\
\text { (MPa) }\end{array}$ \\
\hline 1 & $2 \%$ & 14.76 \\
\hline 2 & $5 \%$ & 22.786 \\
\hline 3 & $7 \%$ & 228.451 \\
\hline 4 & Pure polyester & 57.741 \\
\hline
\end{tabular}

\begin{tabular}{|lll|}
\hline Sr.\# & $\begin{array}{l}\text { Sample ID with various\%age of Cu Nano particles (PPy/CB) in } \\
\text { polyester }\end{array}$ & $\begin{array}{l}\text { Compressive strength } \\
\text { (MPa) }\end{array}$ \\
\hline 1 & $20 \%$ & 97.132 \\
\hline 2 & $15 \%$ & 72.492 \\
\hline 3 & $10 \%$ & 60.669 \\
\hline 4 & $5 \%$ & 22.774 \\
\hline 5 & $2 \%$ & 17.8090 \\
\hline
\end{tabular}

Table 3 Effect of $\mathrm{Cu}$ Nano particles on Compressive strength of hybrid composite

\begin{tabular}{|l|l|l|}
\hline Sr.\# & $\begin{array}{l}\text { Sample ID with various\%age of Cu } \\
\text { Nano particles (PPy/CB) in polyester }\end{array}$ & $\begin{array}{l}\text { Compressive strength } \\
\text { (MPa) }\end{array}$ \\
\hline 1 & $20 \%$ & 97.132 \\
\hline 2 & $15 \%$ & 72.492 \\
\hline 3 & $10 \%$ & 60.609 \\
\hline 4 & $5 \%$ & 22.774 \\
\hline 5 & 296 & 17.8090 \\
\hline
\end{tabular}




\begin{tabular}{|l|l|l|}
\hline Sr.\# & $\begin{array}{l}\text { Sample ID with various \%age of VGCNF and Cu nano particles (PPy/CB ) in } \\
\text { polyester }\end{array}$ & $\begin{array}{l}\text { Compressive strength } \\
\text { (MPa) }\end{array}$ \\
\hline $\mathbf{1}$ & $12 \%$ & 65.899 \\
\hline $\mathbf{2}$ & $10 \%$ & 45.36 \\
\hline $\mathbf{3}$ & $\mathbf{7 \%}$ & 30.101 \\
\hline $\mathbf{4}$ & $\mathbf{5 \%}$ & 13.566 \\
\hline
\end{tabular}

\subsection{Atomic Force Microscopy (AFM)}

Atomic force microscope was employed to get image of the polymer surface. A hybrid composite of PPy/C, $\mathrm{Cu}$ nano powder and VGCNF in polyester was selected and the surface topography was obtained. 6 and 7 shows topographic images of the composite. The PPy/C, $\mathrm{Cu}$ nano powder and VGCNF can easily seen.

\section{Conclusions}

FTIR analysis clearly indicates that the resultant product of PPy is successfully synthesized via chemical route. Moreover it also confirms the coating of polypyrrole on carbon black.

According to UV-visible analysis the PPy coated carbon composites has the ability of adsorption and these composites tend to remove $\mathrm{Cr}(\mathrm{VI})$ ions from $\mathrm{K}_{2} \mathrm{Cr}_{2} \mathrm{O}_{7}$ completely. These composite particles would act as a good adsorbing material for the treatment of waste water.

Electrical conductivity data indicate that by the successive addition of fillers may affects its electrical conductivity as polyester is nonconductive in nature but by the addition of PPy coated carbon blac its conductivity improves which became maximum by the addition of VGCNF which make it more conductive due to its good electrical properties.

TGA analysis indicates that the resultant hybrid composites show good thermal stability which is a good sign for their use in the electric appliances even at high temperature places due to their good thermal stability.

SEM images confirms the synthesis of PPy and PPy coated carbon black composites, moreover these also show the good dispersion of carbon fibers Cu nanoparticles and composite in polyester but some 
agglomerates and voids has also been noticed.

Optical microscopy shows the formation of some primary cracks and holes while the dispersion of $\mathrm{Cu}$ nanoparticles was not good as can be seen from agglomerates of cu nanoparticles.

The compression testing indicated that $\mathrm{Cu}$ nanoparticles and composite imparts good strength to the polyester but as we add VGCNF into it its strength value has been decreased as compare to Cu based hybrid composites. The reason behind is the formation of crack and aggregates during fabrication in hybrid composites are the main hindrance for improving strength in VGCNF based hybrid composites.

\section{Declarations}

\section{Competing interests:}

The authors declare no competing interests.

\section{References}

1. Inzelt, G., Conducting Polymers A New Era in Electrochemistry, Springer, 1, 2008

2. Advani, S.G., Processing and Properties of Nanocomposites, World Scientific, pp. 1, 2007.

3. M. Olek Crabon nano tubes composites Mechanical, Electrical, Optical Properties 2006

4. A.R. Gustavo, M.D. Rubaianes Carbon nano tubes for electrochemical biosencing Talanta 74 (2001) 291

5. Epstein, A.J., Electrical Conductivity in Conjugated Polymers, Conductive Polymers and Plastics in Industrial Applications, Platics Design Library, 1, 93, 1999

6. Freund, M.S., Deore B., Self-Doped Conducting Polymers, Wiley, pp.1,2, 10-12, 2006.

7. Duke, C.B., Schein, L.B., 1980. Organic solids: is energy-based theory enough? Phys. Today 33, 4248.

8. Bloor, D., Movaghar, B., 1983. Conducting polymers. IEEE Proceedings 130, 225-232

9. Epstein, A.J., Electrical Conductivity in Conjugated Polymers, Conductive Polymers and Plastics in Industrial Applications, Platics Design Library, 1, 93, 1999

10. Inzelt, G., Conducting Polymers A New Era in Electrochemistry, Springer, 1, 2008

11. Advani, S.G., Processing and Properties of Nanocomposites, World Scientific, pp. 1, 2007.

12. Kricheldorf, H.R., Nuyken, O., Swift, G., Handbook of Polymer Synthesis, Marcel Dekker., Ch. 12, pp 1,3,4, USA, 2005

13. Wikipedia, The Free Encylopedia last accessed on 10th May 2009.

14. Ansari, R., Polypyrrole conducting electroactive polymers: Synthesis and stability studies, E-Journal of Chemistry, Vol.3, No.13, pp 186-201, 2006 
15. Duke, C.B., Schein, L.B., 1980. Organic solids: is energy-based theory enough? Phys. Today 33, 4248.

16. Sanjay, K. Mazumdar, Composites Manufacturing Materials, Product and Process Engineering, CRC Press LLC, USA, pp 4-6, 2002.

17. Kricheldorf, H.R., Nuyken, O., Swift, G., Handbook of Polymer Synthesis, Marcel Dekker., Ch. 12, pp 1,3,4, USA, 2005

Figures

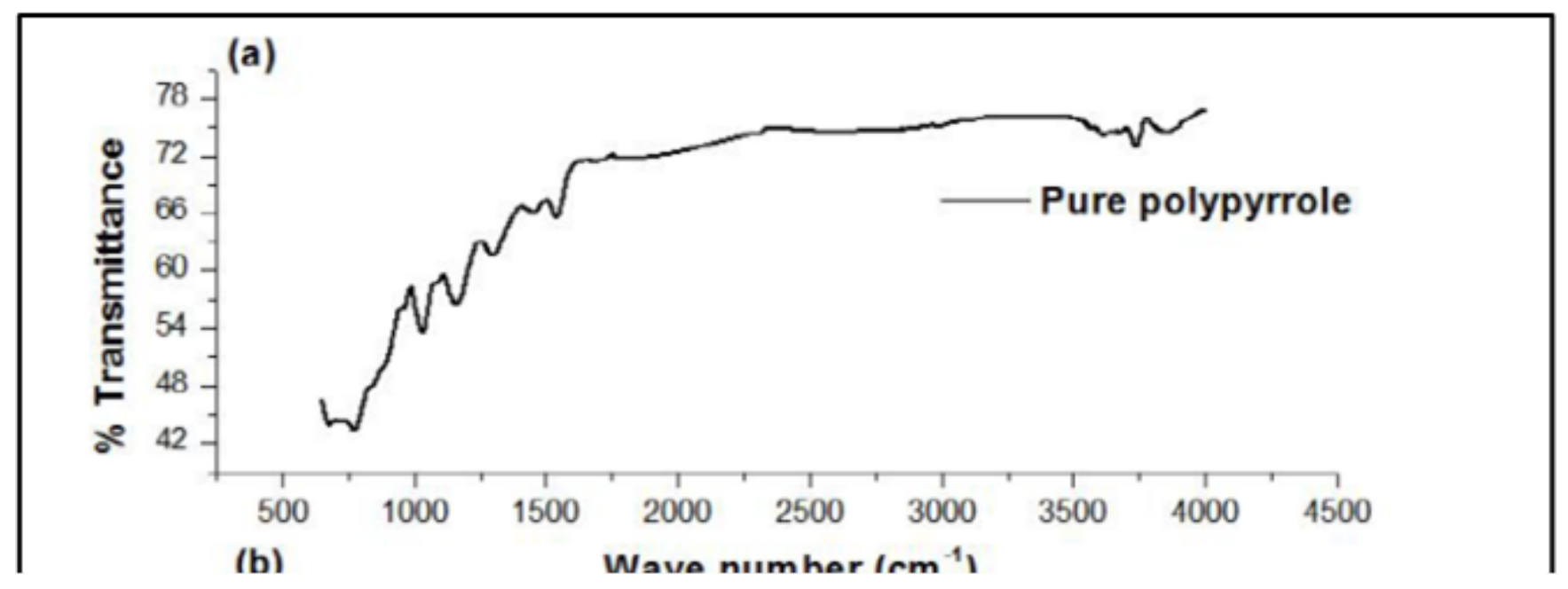

Figure 1

FTIR Spectra of pure PPy and 15 wt \% of PPy coated carbon black composite taken at room temperature

\section{Figure 2}

TGA comparison of Pure Polyester and the Hybrids composites 


\section{Figure 3}

SEM images of (a) polypyrrole (b) Composite PPy/CB (c,d,e) Hybrid composites

\section{Figure 4}

Investigation of 5\% VGCNF/15\%Cu particles /5\%PPy/CB/P.E. hybrid composite under optical microscope

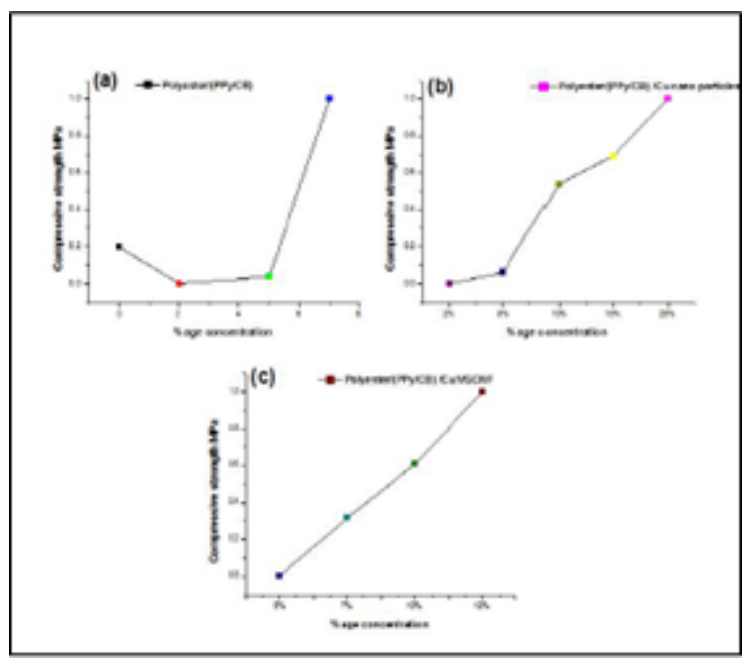

Figure 5

Results of Compression testing of different hybrid composites 

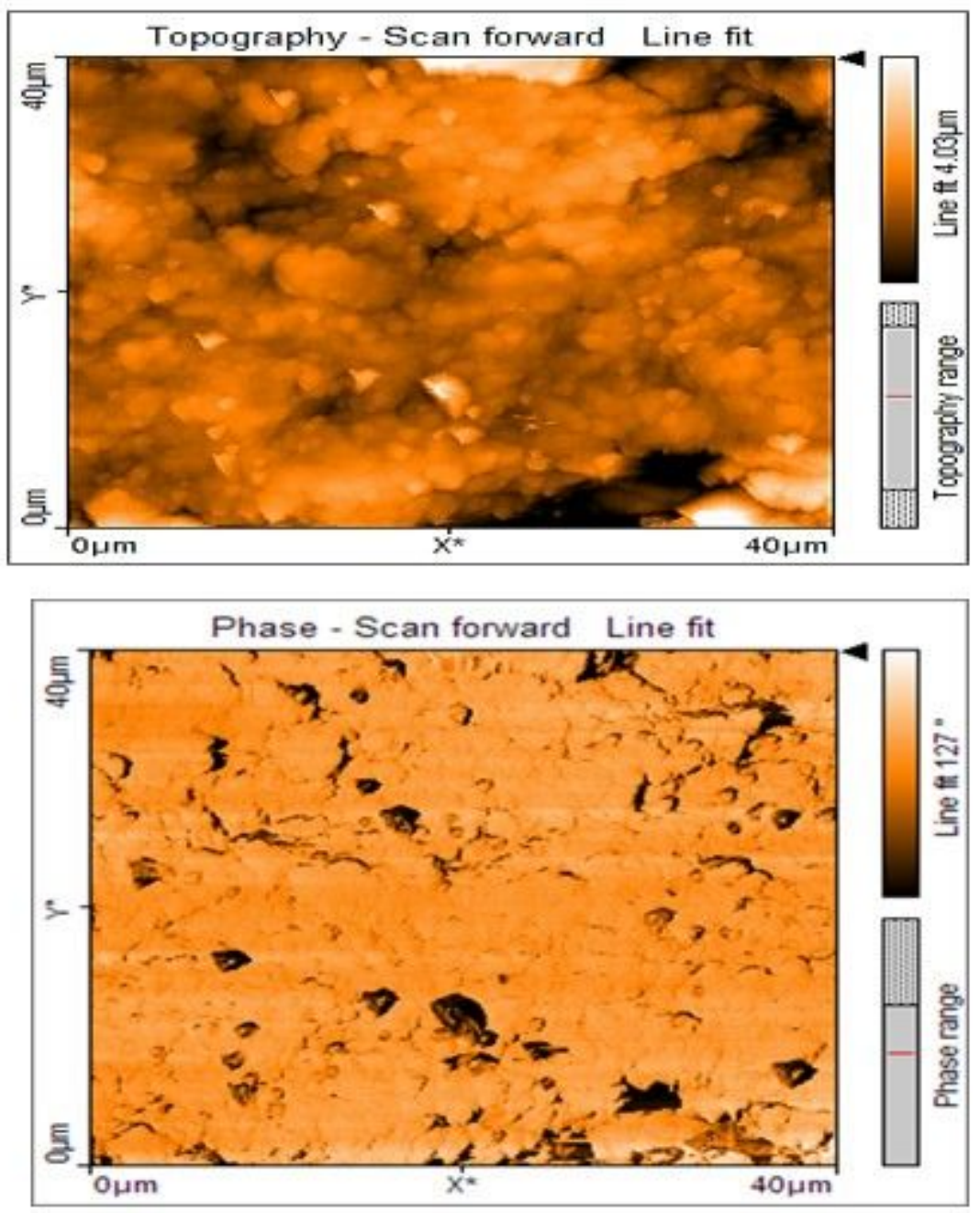

Figure 6

Fig 4.8 Topographic image of hybrid composite consisting of 5\% PPy/C, 5\% Cu and 5\% VGCNF dispersed in Polyester (Phase and topographic scans) 